\title{
Pengembangan Area Etika, Moral, Mediko Legal dan Profesionalisme serta Keselamatan Pasien dalam Kurikulum Berbasis Kompetensi
}

\author{
Yani Istadi \\ Fakultas Kedokteran Universitas Islam Sultan Agung \\ Semarang
}

\begin{abstract}
Introduction: The existence of the application of competency-based curriculum (CBC) with the strategy of problem based learning $(P B L)$ has influenced the learning process of ethics and professionalism. It poses a challenge for every medical school to develop the new curriculum. There has been a controversy on the model of the curriculum development. Objective: This article describes several educational studies on ethics and professionalism and proposes one curriculum model.

Discussion: The method used in the study of ethics is directed in accordance with the level of education and the complexity of the expertise field. Determination of the material depends on the competence and the expected outcomes.

Challenges in the assessment and ethics and professionalism must be faced.

Conclusion: The development of a curriculum that will better ensure the achievement of competence 7 th SKDI area. Therefore, the curriculum makers must continue to innovate.
\end{abstract}

Keywords: ethics and professionalism, curriculum development

\begin{abstract}
Abstrak
Pendahuluan: Keberadaan penerapan kurikulum berbasis kompetensi dengan strategi problem based learning (PBL) telah mempengaruhi proses pembelajaran etik dan profesionalisme. Sebuah tantangan setiap institusi pendidikan kedokteran mengembangkan kurikulum baru pada area ini. Adanya kontroversi pada pengembangan area ini di dalam kurikulum.

Tujuan: Artikel ini menggambarkan beberapa penelitian pendidikan etik dan profesionalisme dan menawarkan satu contoh model pengembangannya

Pembahasan: Metode yang digunakan dalam pembelajaran etik diarahkan sesuai dengan tingkat pendidikan dan kompleksitas bidang keahlian. Penentuan materi tergantung pada kompetensi dan luaran yang diharapkan. Tantangan dalam asessment etik dan profesionalisme harus dihadapi.

Kesimpulan: Pengembangan kurikulum yang baik akan menjamin pencapaian kompetensi area ke-7 SKDI. Oleh karena itu, pembuat kurikulum harus terus berinovasi.
\end{abstract}

Kata Kunci: etik dan profesionalisme, pengembangan kurikulum

Korespondensi: FK Unissula JL. Raya Kaligawe Km.4 Semarang, 50112. PO Box 1054/SM, 08156534492 Fax: (024) 6594366

Email: bosse-fk@yahoo.co.id 


\section{PENDAHULUAN}

Pada saat ini pendidikan kedokteran sedang mengadakan inovasi pada kurikulum. Kurikulum yang terselenggara adalah kurikulum berbasis kompetensi. Kurikulum berbasis kompetensi ini merupakan pendidikan berbasis luaran (outcome), artinya kompetensi yang ada berawal dari luaran yang diharapkan oleh masyarakat. Salah satu kompetensi yang harus dipunyai seorang dokter adalah area etika, moral, mediko legal dan profesionalisme serta keselamatan pasien. Area ini didesain untuk memfasilitasi tanggung jawab perilaku dan keterampilan pengembangan profesi yang dibutuhkan mahasiswa untuk praktek klinik.

Area ini merupakan salah satu materi pembelajaran kurikulum kedokteran. Pembelajaran etik dan profesionalisme merupakan komponen penting pendidikan kedokteran, yang secara empirik masih sedikit informasi di dalam kurikulum. Dahulu materi etika dan hukum kedokteran diselenggarakan dalam bentuk mata kuliah. Metode pembelajaran yang digunakan hanya satu yaitu kuliah. Materi yang diajarkan sebagian besar berisi pengetahuan sedangkan sikap merupakan hidden curriculum. Evaluasinya masih menilai pengetahuan.

Adanya penerapan kurikulum berbasis kompetensi (KBK) dengan strategi pendekatan problem based learning (PBL) mempunyai pengaruh terhadap proses pembelajaran etik dan profesionalisme. Banyak kontroversi di kalangan pendidik tentang cara efektif di dalam mengajarkan area ini apakah proses pembelajarannya dibuat dalam satu blok/modul habis atau disebar ke dalam blok-blok/ modul-modul sepanjang proses pendidikan. Suatu tantangan tersendiri bagi setiap fakultas kedokteran untuk mengembangkan area tersebut di dalam kurikulumnya.

\section{PEMBAHASAN}

Prinsip Dasar Pengembangan Pembelajaran Area Etika, Moral, Mediko Legal dan Profesionalisme serta Keselamatan Pasien.

Penerapan kurikulum berbasis kompetensi (KBK) dengan strategi pendekatan problem based learning (PBL) mempunyai pengaruh terhadap proses pembelajaran etik dan profesionalisme termasuk di dalamnya cara mengembangkan pembelajarannya. Beberapa literatur yang membahas tentang prisip-prinsip dasar pengembangan pembelajaran pada area ini diantaranya:

1. Menurut Emilia dan Harsono ${ }^{1}$ pada prinsipnya mengajarkan etik dan profesionalisme sebaiknya menggunakan pendekatan yang sistematik, yaitu pertama kali harus diidentifikasi kompetensi yang memang ingin dicapai melalui pembelajaran ini. Kedua ditetapkan komponen kurikulum yang cocok untuk mengenalkan konsep etik dan profesionalisme. Ketiga, pembelajaran ini harus bersifat eksplisit dan masuk dalam aturan formal institusi. Prinsip keempat adalah jangan sekalikali mengkompensasikan aspek etik dan profesionalisme dengan penilaian aspek lain karena justru tidak membantu pembinaan kompetensi etik dan profesionalisme. Kelima, mahasiswa harus diberi kesempatan dan keterampilan untuk melakukan refleksi terhadap proses pembelajaran yang telah dijalaninya.

2. Integrasi penuh di dalam pengajaran etik dan hukum kedalam kurikulum direkomendasikan, terutama pada fase rotasi klinik. ${ }^{2}$ Sebaiknya setiap bagian klinik mempunyai pembahasan isu etik dan legal yang relevan di bagiannya. ${ }^{3}$

3. Keterampilan pembuatan keputusan etik merupakan bagian integrasi dari proses pembuatan keputusan klinik sehingga proses pembelajarannya sebaiknya diintegrasikan ke dalam komponen pembelajaran klinik. ${ }^{4}$

4. Pembelajaran etik dan hukum kedokteran seperti materi kurikulum inti yang lain tentunya dinilai secara formal juga. ${ }^{5}$

5. Para ahli pendidikan menekankan pembelajaran yang berpusat pada mahasiswa maka langkah pertama yang dilakukan adalah identifikasi kebutuhan dari mahasiswa. ${ }^{6}$

6. Pendidikan etik dilakukan dengan pendekatan integrasi antara pelayanan pasien dan etika itu sendiri. ${ }^{?}$

\section{Metode Pembelajaran}

Metode yang digunakan dalam pembelajaran etik tentunya diarahkan sesuai dengan tingkat pendidikan mahasiswa, dan tingkat kompleksitas pelayanan pasien dan bidang keahliannya. Oleh karena itu metode pendekatan pembelajaran yang digunakan bagi dokter 
muda akan berbeda sekali dengan residen. ${ }^{7}$ Beberapa literatur tentang metode pembelajaran etik dan profesionalisme, diantaranya menyebutkan bahwa:

1. Pembelajaran melalui diskusi kelompok kecil dengan menggunakan studi kasus di dalam kurikulum terintegrasi dapat secara efektif mengembangkan nilai normatif profesi kedokteran. Semakin banyak kesempatan di dalam diskusi kelompok kecil maka efektifitasnya semakin besar. ${ }^{5}$ Pembelajaran ini juga memberikan pengaruh besar terhadap penalaran moral (moral reasoning) daripada kuliah atau kelas besar. ${ }^{2,8}$ Temuan dari Self et al ${ }^{9}$ menunjukkan bahwa diskusi kelompok kecil menimbulkan efek penalaran moral ketika mahasiswa terpapar 20 jam atau lebih didalam proses pembelajaran. Menurut Kauffman et allo, alasan mengapa diskusi kelompok kecil lebih efektif daripada kuliah atau kelas besar adalah kemungkinan karena di dalam proses diskusi kelompok kecil terjadi hubungan yang kondusif yang memungkinkan adanya transformative learning.

2. Adanya integrasi teori dengan praktek, melakukan bimbingan yang mendukung/positif, pembelajaran bersifat bertahap sepanjang kurikulum, dan disertai dengan ilustrasi yang konkrit. ${ }^{11}$

3. Adanya pola interaktif dan tidak menggurui, berbasis kasus, pendekatan menyeluruh dan manusiawi, melihat pasien/ kasus secara langsung maupun tidak langsung (melalui klip video atau skenario kasus), mengedepankan umpan balik positif terhadap proses pembelajaran, kurikulum terstruktur dan berjenjang. ${ }^{12}$

4. Pembelajaran dengan melibatkan mahasiswa terjun ke rumah sakit dengan melihat kasus etik di lingkungan sekitar yang kemudian kasus tersebut diangkat di dalam suatu forum. Forum tersebut diarahkan oleh seorang pakar bioetik yang telah mempersiapkan sumber pustaka. Forum semacam ini dinilai sangat efektif karena mahasiswa diajarkan sesuai dengan kenyataan yang dialaminya. Forum ini bersifat informasi/ bimbingan sehingga mahasiswa tidak perlu takut untuk dinilai. ${ }^{13}$ Spike ${ }^{19}$ menyarankan setiap rumah sakit pendidikan sebaiknya selalu ada seorang ahli etik yang bekerja full-time guna membantu jika seseorang ingin menanyakan alternatif pertimbangan di dalam proses pelayanan kesehatan

5. Adanya pembelajaran dengan menggunakan pendekatan kuliah yang mengutamakan metode cerita, diskusi interaktif dengan kombinasi debat etik, sesi panel ahli, bermain peran, tugas-tugas yang harus diselesaikan, dan mengamati situasi praktek yang ada. ${ }^{1}$

6. Menggunakan dosen sebagai role model. Role model lebih efektif daripada formal coursework oleh karena dosen berkeinginan untuk mengakui kekurangan ketika berbagi pengalaman pribadi mereka dengan mahasiswa sehingga hal ini memainkan peran penting didalam menumbuhkan sikap kritis yang konstruktif terhadap mahasiswa. ${ }^{14}$ Data empiris lain juga menguatkan bahwa mahasiswa lebih terpengaruh oleh role model daripada formal coursework. ${ }^{15}$ Hafferty dan Franks ${ }^{16}$ menyarankan bahwa role model dapat membantu menetralkan efek dari hidden curriculum.

7. Visite besar etik dan kursus etik berbasis web. ${ }^{7}$

8. Menggunakan pendekatan Bristol yaitu: kurikulum terstruktur dan berjenjang, pembelajaran secara aktif melibatkan mahasiswa, belajar berdasarkan kasus, kasus-kasus etik yang dipelajari berkenaan dengan pasien, pembahasan teori disertai dengan aplikasi klinik, pendekatan menyeluruh dan manusiawi, disampaikan secara interaktif dan tidak menggurui, adanya suasana yang aman dalam berdiskusi, kritik yang muncul bersifat membangun dan diberikan secara berkesinambungan dan bila memungkin-kan adanya tim ajar etik dalam mengorganisasi dan menjalankannya. ${ }^{17}$

\section{Materi Pembelajaran Etik dan Profesionalisme}

Dalam menentukan materi apa yang akan diberikan tentunya tergantung pada kompetensi dan luaran yang diharapkan. Standar Kompetensi Dokter telah mengatur hal tersebut tetapi harus dijabarkan lagi ke dalam sasaran belajar. Beberapa literatur yang menyarankan tentang materi pembelajaran etik diantaranya:

1. Autonomy, inform consent, kerahasiaan, alkohol, hak asasi manusia, negligence dan malpraktek. ${ }^{5}$

2. Komitmen untuk belajar, keterampilan komuni-kasi, bekerjasama sebagai anggota tim, dan integrity. ${ }^{8}$ 
3. Inform consent, patient autonomy, beneficience, keadilan, kerahasiaan dan etika klinik. ${ }^{19}$

4. Inform consent, hubungan interprofessional, inter-aksi dengan keluarga, keterampilan komunikasi dan perawatan end-of life. 6

5. Etika kedokteran umum, etika kedokteran khusus, etika dalam masalah klinik, etika dalam masalah penelitian kedokteran, dan etika dalam masalah reproduksi manusia. ${ }^{20}$

\section{Asesmen}

Asesmen etik dan profesionalisme dalam pengetahuan, keterampilan dan sikap merupakan tantangan yang penting. Pengetahuan faktual dapat dievaluasi melalui ujian langsung menggunakan ujian tertulis (MEQ, Essay atau MCQ). Keterampilan dapat menggunakan objective standardized clinical examination (OSCE). Sedangkan untuk profesionalisme menggunakan $360^{\circ}$ reviews (peer, perawat dan lainnya) atau disediakan form elektronik evaluasi. ${ }^{18,21}$

Contoh Implementasi area Etika, Moral, Mediko Legal dan Profesionalisme serta Keselamatan Pasien yang dikembangkan di Fakultas Kedokteran Unissula

Fakultas Kedokteran Unissula mulai mengembangkan materi pembelajaran area Etika, Moral, Mediko Legal dan Profesionalisme serta Keselamatan Pasien sejak 2007-sekarang. Sebelumnya materi etika dan hukum kedokteran masih mengacu pada kurikulum yang lama, dan pengorganisasian materi dilaksanakan sebagai matakuliah. Setelah 2007, materi pembelajaran dikembangkan sesuai dengan tingkat kompetensi dan learning outcome yang diharapkan oleh Standar Kompe-tensi Dokter Indonesia. Oleh karena isi kurikulum diintegrasikan baik secara horizontal maupun vertikal maka materi pada area ini juga diintegrasikan ke dalam modul-modul dan disesuaikan dengan temanya artinya diorganisasi secara terstruktur dan berjenjang. Struktur Kurikulum terdiri dari program pendidikan sarjana (fase 1 dan 2) dan program pendidikan profesi dokter (fase 3).

Pada Fase 1 pembelajaran ditekankan pada aspek teoritik dari etika, legal dan profesionalisme serta nilai inti kedokteran. Fase 2 ditekankan pada aspek penanganan pasien seperti prima facie; KODEKI dan hukum kedokteran; sumpah; UUPK; hak asasi manusia; keterampilan penyelesaian masalah terkait etika, legal, dan hukum dengan menggunakan skenario kasus/klip video sedangkan fase 3 (klinik) ditekankan pada aspek hukum pelayanan kedokteran dan RS; pengetahuan dan keterampilan surat-surat yang berkekuatan hukum; keselamatan pasien; dan keterampilan penyelesaian masalah terkait etika, legal, dan hukum dengan menggunakan kasus nyata. Tabel 1 menunjukkan contoh materi area 7 yang dimasukkan ke dalam kurikulum.

Tabel 1. Sebaran materi area 7 pada tahun pertama

\begin{tabular}{|c|c|c|c|c|}
\hline LEARNING OUTCOME & SASARAN BELAJAR & MATERI & $\begin{array}{l}\text { METODE } \\
\text { PEMBELAJARAN }\end{array}$ & $\begin{array}{l}\text { NAMA } \\
\text { MODUL }\end{array}$ \\
\hline \multirow[t]{2}{*}{$\begin{array}{l}\text { - Menjelaskan hubungan } \\
\text { dokter-pasien } \\
\text { - Menjelaskan aspek etika } \\
\text { dalam penanganan pasien } \\
\text { sesuai standar profesi } \\
\text { - Menjelaskan hukum terkait } \\
\text { kcrahasiaan dan } \\
\text { kepercayaan pasien }\end{array}$} & $\begin{array}{l}\text { - Mampu menjelaskan } \\
\text { konscp hukum hubungan } \\
\text { dokter-pasien. } \\
\text { - Mampu menjelaskan asas- } \\
\text { asas hubungan dokter- } \\
\text { pasien. } \\
\text { - Mampu menjclaskan hak } \\
\text { dan kewajiban dokter- } \\
\text { pasien. }\end{array}$ & $\begin{array}{l}\text { Hubungan } \\
\text { dokter-pasicn } \\
\text { (definisi etik } \\
\text { dan legal) }\end{array}$ & Kuliah Pakar & Komunikasi \\
\hline & $\begin{array}{l}\text { - Menjelaskan definisi dan } \\
\text { terminologi informed } \\
\text { consent. } \\
\text { - Menjelaskan landasan } \\
\text { hukum informed consent. } \\
\text { - Menjelaskan cara } \\
\text { membuat informed consent. } \\
\text { - Memahami hakekat } \\
\text { informed consent. }\end{array}$ & $\begin{array}{l}\text { Kerahasiaan } \\
\text { medik dan } \\
\text { Inform } \\
\text { consent }\end{array}$ & Kuliah Pakar & Hematopoetin \\
\hline
\end{tabular}




\begin{tabular}{|c|c|c|c|c|}
\hline LEARNING OUTCOME & SASARAN BELAJAR & MATERI & $\begin{array}{l}\text { METODE } \\
\text { PEMBELAJARAN }\end{array}$ & $\begin{array}{l}\text { NAMA } \\
\text { MODUL }\end{array}$ \\
\hline & $\begin{array}{l}\text { - Mampu menjelaskan } \\
\text { terminologi kerahasiaan } \\
\text { medik. } \\
\text { - Mampu menjelaskan aspek } \\
\text { hukum kerahasiaan medik. } \\
\text { - Mampu menjclaskan hal- } \\
\text { hal yang dapat melepaskan } \\
\text { kerahasiaan medik }\end{array}$ & & & \\
\hline & $\begin{array}{l}\text { - Menjelaskan definisi } \\
\text { rekam medik. } \\
\text { - Menjelaskan komponen } \\
\text { rekam medik. } \\
\text { - Menjelaskan kegunaan } \\
\text { rekam medik. } \\
\text { - Menjelaskan aspek hukum } \\
\text { rekam medik. }\end{array}$ & Rekam medik & Kuliah Pakar & Hematopoetin \\
\hline $\begin{array}{l}\text { Menunjukkan kepercayaan } \\
\text { dan saling menghormati } \\
\text { dalam hubungan dokter } \\
\text { pasien dengan bermain } \\
\text { peran }\end{array}$ & $\begin{array}{l}\text { Menunjukkan kepercayaan } \\
\text { dan saling menghormati } \\
\text { dalam hubungan dokter } \\
\text { pasien dengan bermain } \\
\text { peran }\end{array}$ & $\begin{array}{l}\text { Keterampilan } \\
\text { komunikasi }\end{array}$ & Skill Iab & Komunikasi \\
\hline $\begin{array}{l}\text { Menjelaskan pengertian dan } \\
\text { cara berempati dengan baik }\end{array}$ & $\begin{array}{l}\text { - Menjelaskan pengertian } \\
\text { empati } \\
\text { - Menjelaskan tujuan } \\
\text { berempati } \\
\text { - Menjelaskan manfaat } \\
\text { berempati } \\
\text { - Menjelaskan cara } \\
\text { berempati dengan baik }\end{array}$ & $\begin{array}{l}\text { Praktek } \\
\text { kedokteran } \\
\text { empatik }\end{array}$ & Kuliah Pakar & Komunikasi \\
\hline $\begin{array}{l}\text { Menunjukkan rasa empati } \\
\text { dengan cara bermain peran }\end{array}$ & $\begin{array}{l}\text { Menunjukkan rasa empati } \\
\text { dengan cara bermain peran }\end{array}$ & $\begin{array}{l}\text { Keterampilan } \\
\text { empati }\end{array}$ & Skill lab & Komunikasi \\
\hline $\begin{array}{l}\text { Menjelaskan cara } \\
\text { menanggapi masukan orang } \\
\text { lain secara konstruktif }\end{array}$ & $\begin{array}{l}\text { - Menjelaskan pengertian } \\
\text { umpan balik (feed back) } \\
\text { - Menjelaskan teori } \\
\text { mekanisme feed back } \\
\text { - Menjelaskan cara } \\
\text { menanggapi masukan } \\
\text { orang lain secara } \\
\text { konstruktif }\end{array}$ & $\begin{array}{l}\text { "Constructive } \\
\text { Feed-back" }\end{array}$ & Kuliah Pakar & Komunikasi \\
\hline $\begin{array}{l}\text { Menjelaskan perbedaan } \\
\text { karakter individu, gaya } \\
\text { hidup dan budaya dari } \\
\text { pasien dan sejawat }\end{array}$ & $\begin{array}{l}\text { - Menjelaskan pengertian } \\
\text { budaya } \\
\text { - Menjelaskan pengertian } \\
\text { gaya hidup } \\
\text { - Menjclaskan pengertian } \\
\text { karakter individu } \\
\text { - Menjclaskan perbedaan } \\
\text { karakter individu, gaya } \\
\text { hidup dan budaya dari } \\
\text { pasien dan sejawat }\end{array}$ & $\begin{array}{l}\text { Anthropologi } \\
\text { kesehatan }\end{array}$ & Kuliah Pakar & $\begin{array}{l}\text { Biopsikososio } \\
\text { kultural }\end{array}$ \\
\hline
\end{tabular}




\begin{tabular}{|c|c|c|c|c|}
\hline LEARNING OUTCOME & SASARAN BELAJAR & MATERI & $\begin{array}{l}\text { METODE } \\
\text { PEMBELAJARAN }\end{array}$ & $\begin{array}{l}\text { NAMA } \\
\text { MODUL }\end{array}$ \\
\hline $\begin{array}{l}\text { Mcmahami hctcrogcnitas } \\
\text { persepsi yang berkaitan } \\
\text { dengan usia, gender, } \\
\text { orientasi seksual, etnis, } \\
\text { kecacatan dan status sosial } \\
\text { ekonomi } \\
\text { - Menjelaskan bahwa tiap } \\
\text { individu mempunyai } \\
\text { kontribusi dan peran yang } \\
\text { berharga tanpa } \\
\text { memandang status sosial }\end{array}$ & $\begin{array}{l}\text { - Mcmahami hetcrogcnitas } \\
\text { persepsi yang berkaitan } \\
\text { dengan usia, gender, } \\
\text { orientasi seksual, etnis, } \\
\text { kecacatan dan status sosial } \\
\text { ekonomi } \\
\text { - Menjelaskan bahwa tiap } \\
\text { individu mempunyai } \\
\text { kontribusi dan peran yang } \\
\text { berharga tanpa } \\
\text { memandang status sosial }\end{array}$ & Etika sosial & Kuliah Pakar & $\begin{array}{l}\text { Kepedulian } \\
\text { terhadap } \\
\text { masyarakat } \\
\text { dan } \\
\text { lingkungan }\end{array}$ \\
\hline $\begin{array}{l}\text { - } \text { Memahami Etika } \\
\text { Kedokteran } \\
\text { - Mcnjclaskan sikap } \\
\text { profesional } \\
\text { - Menjelaskan perilaku } \\
\text { profesional tanpa } \\
\text { membedakan status sosial }\end{array}$ & $\begin{array}{l}\text { - Menjelaskan pengertian } \\
\text { etika. } \\
\text { - Mcnjclaskan } \\
\text { perkembangan etika serta } \\
\text { etika kedokteran } \\
\text { - Menjelaskan prinsip- } \\
\text { prinsip dasar } \\
\text { bioetika/kaidah dasar } \\
\text { bioetika (KDB). } \\
\text { - Menjelaskan definisi } \\
\text { perilaku profesional } \\
\text { - Menjelaskan ciri-ciri } \\
\text { perilaku profesional } \\
\text { - Menjelaskan perilaku yang } \\
\text { tidak profesional }\end{array}$ & $\begin{array}{l}\text { Pengantar etika } \\
\text { kedokteran dan } \\
\text { profesionalisme }\end{array}$ & Kuliah Pakar & $\begin{array}{l}\text { Prioritas } \\
\text { masalah } \\
\text { kesehatan di } \\
\text { Indonesia }\end{array}$ \\
\hline
\end{tabular}

Penggunaan metode pembelajaran pun juga disesuaikan dengan fase pembelajaran, tingkat kompetensi dan learning outcome yang diharapkan. Pada fase 1, sebagian besar metode pembelajaran menggunakan metode kuliah interaktif dan sebagian kecil skill lab (pembelajaran di skill lab ditujukan untuk keterampilan etik dan profesionalisme). Fase 2, metode yang digunakan sudah ada variasi yaitu menggunakan metode small group discussion yang membahas kasus masalah-masalah etik klinis dalam bentuk skenario, kuliah interaktif dengan menggunakan skenario kasus sebagai "gaining attention", keterampilan medik yang disisipkan komponen penilaian profesionalisme. Sedangkan fase 3, metode pembelajarannya ditekankan pada pembelajaran dengan pasien atau masyarakat di wahana pendidikan klinik. Mahasiswa dihadapkan dengan kasus-kasus etik klinik yang mereka jumpai selama mereka pendidikan di tempat tersebut. Metode pembelajarannya menggunakan tutorial klinik, pleno, sesi journal reading tentang etik dan laporan kasus. ${ }^{22}$

\section{KESIMPULAN}

Dari penjelasan singkat di atas dapat diambil kesimpulan bahwa adanya penerapan kurikulum berbasis kompetensi (KBK) dengan strategi pendekatan problem based learning (PBL) memaksa para pengembang kurikulum untuk melakukan inovasi. Area Etika, Moral, Mediko Legal dan Profesionalisme serta Keselamatan Pasien merupakan area ke 7 dari standar kompetensi dokter yang memfasilitasi tanggung jawab perilaku dan keterampilan pengembangan profesi yang dibutuhkan mahasiswa untuk praktek klinik. Agar tercapainya area kompetensi ini diperlukan suatu sistem pengembangan kurikulum yang baik mulai dari tingkat kurikulum makro, kurikulum meso dan kurikulum mikro. Pengertian yang baik tentang etik kedokteran merupakan sentral dalam menuju pelayanan kedokteran yang baik. 


\section{DAFTAR PUSTAKA}

1. Emilia $\mathrm{O}$, Harsono. Mengajar etik dan profesional-isme. Jurnal Pendidikan Kedokteran dan Profesi Kesehatan Indonesia. 2007;2(4): 126-9.

2. Goldie J, Schwartz L, Mc Connachie A, Morrison J. The impact of a modern curriculum on students' proposed behaviour on meeting ethical dilemmas. Medical Education [Internet]. 2004 [cited 2009 Jul 22];38(9):942-9. Available from: MEDLINE.

3. UK Consensus Statement. Teaching medical ethics and law within medical education: a model for the UK core curriculum. Journal Medical Ethics [Internet]. 1998 [cited 2009 Jul 22];24(3): 188-92.Available from: http:/ /www.ncbi.nlm.nih.gov/pmc/articles/PMC1377522.

4. Goldie J. Review of ethics curricula in undergraduate medical education. Medical Education [Internet]. 2000 [cited 2009 Jul 30];34(2): 108-19. Available from: MEDLINE.

5. Goldie J, Schwartz L, Mc Connachie A, Morrison J. The impact of three years ethics teaching, in integrated medical curriculum, on students' proposed behaviour on meeting ethical dilemmas. Medical Education [Internet]. 2002 [cited 2009 Aug 2];36(5): 489-97. Available from: MEDLINE.

6. Goold SD and Stern DT. Ethics and professionalism: what does a resident need to learn? The American Journal of Bioethic [Internet]. 2006 [cited 2009 Aug 2];6(4): 9-17. Available from: http://www.ncbi.nlm. nih.gov/pubmed/16885093.

7. Bolin JN. Strategies for incorporating professional ethics education in graduate medical programs. The American Journal of Bioethics [Internet]. 2006 [cited 2009 Aug 7];6(4): 35-6. Available from: http://www. ncbi.nlm.nih.gov/pubmed/16885103.

8. Self DJ, Wolinsky FD, Baldwin DC. The effect of teaching medical ethics on medical students' moral reasoning. Academic Medicine [Internet]. 1989 [cited 2009 Jul 20;64(12): 755-9. Available from: http:// www.ncbi.nlm.nih.gov/pubmed/2590358.

9. Self DJ, Olivarez M, Baldwin DC. The amount of small group case-study discussion needed to improve the moral reasoning skills of medical students. Academic Medicine [Internet]. 1998 [cited 2009 Jul 19];73(5): 521-3. Available from: http://www.ncbi. nlm.nih.gov/ pubmed/9609864.

10. Kaufman DM, Mann KV, Jennett PA. ASME Medical Education Booklet. Teaching and learning in medical education: how can theory inform practice. Medical Education. 2000;34: 20-2. Available from: MEDLINE.

11. Li B. Ethics teaching in medical school. Hastings Center Report. 2000;30( Suppl 4):S30-2.
12. Swick HM, Szenas P, Danoff D, Whitcomb ME. Teaching professionalism in undergraduate medical education. JAMA [Internet]. 1999 [cited 2009 Aug 16]; 282(9): 830-2. Available from: http://www.ncbi. nlm.nih.gov/pubmed/10478688.

13. Spike JP. Residency education in clinical ethics and professionalism: not just what, but when, where, and how ought residents be taught? The American Journal of Bioethics [Internet]. 2006 [cited 2009 Aug 16]; 6(4): 23-5. Available from: http://www.ncbi.nlm.nih. gov/ pubmed/16885097.

14. Goldie J, Schwartz L, Mc Connachie A, Morrison J. Impact of a new course on students' potential behaviour on encountering ethical dilemmas. Medical Education [Internet]. 2001 [cited 2009 Aug 16];35(3): 295-302. Available from: MEDLINE.

15. Sulmasy DP, Terry PB, Faden RR, Levine DM. Longterm effects of ethics education on the quality of care for patients who have do-not-resuscitate orders. J Gen Intern Med [Internet]. 1994 [cited 2009 Aug 20];9: 622 6. Available from: http://www.ncbi.nlm.nih.gov/ pubmed/7853071.

16. Hafferty FW, and Franks R. The hidden curriculum, ethics teaching and the structure of medical education. Academic Medicine [Internet]. 1994 [cited 2009 Aug 20];69(11): 861-71. Available from: http://www.ncbi. nlm.nih.gov/pubmed/7945681.

17. Brennan MG. Ethics and attitudes. In: Dent JA, Harden RM, editors. A Practical Guide for Medical Teachers, $2^{\text {nd }}$ ed. Edinburgh: Elsevier Churchill Livingstone 2005; 248-55.

18. Arnold L. Assessing professional behavior: yesterday, today, and tomorrow. Academic Medicine [Internet]. 2002 [cited 2009 Aug 22];77(6): 502-15. Available from: http://www.ncbi.nlm.nih.gov/pubmed/ 12063194.

19. Robin ML and Caniano DA. Analysis of clinical bioethics teaching in pediatric surgery residency. Journal of Pediatric Surgery [Internet]. 1998 [cited 2009 Aug 22];33(2): 373-7. Available from: http:// www.ncbi.nlm.nih.gov/pubmed/9498421.

20. Samil RS. Etika kedokteran Indonesia. Edisi kedua. Jakarta: Yayasan Bina Pustaka Sarwono Prawiro-hardjo; 2001.

21. Lynch DC, Surdyk PM, and Eiser AR. Assessing professionalism: a review of the literature. Medical Teacher [Internet]. 2004 [cited 2009 Sep 2];26(4): 366 73. Available from: MEDLINE.

22. Istadi Y. Blue print implementasi area etika, moral, mediko legal dan profesionalisme serta keselamatan pasien fakultas kedokteran Unissula Semarang. Disampaikan pada pertemuan dengan HWS Dikti; 2008. 